\title{
The Effects of Cationization on Dyeing Properties of Cotton Fabric Dyed with Marigold and Rose
}

\author{
Matrikan Nutchawanit, Chutimon Satirapipathkul, and Rattanaphol Mongkholrattanasit
}

\begin{abstract}
A cationizing agent was used for increasing the color yield, in terms of the Kubelka-Munk values (color strength, $K / S$ ). Cotton fabrics were dyed using the extract of waste marigold and rose. This work was to study the optimum of time, temperature and concentration in cationizing process on dyed cotton. The $K / S$ and color values $\left(L^{*}, a^{*}, b^{*}\right)$ were measured to discover the suitable condition from color value and color strength estimation, cotton fabric cationized with 10 $\mathrm{g} / \mathrm{L}$ of cationizing-agent concentration for 30 minutes at the $5^{\circ} \mathrm{C}$ showed the highest $K / S$. In case of roses, the best condition is treated with cationizing-agent concentration of $15 \mathrm{~g} / \mathrm{L}$ for 15 minutes at $50^{\circ} \mathrm{C}$. The obtainable results revealed that the color strength of cationized cotton fabrics were increased when compared to $K / S$ of untreated cotton up to $34.26 \%$ and $331.91 \%$ for marigold and rose dyes, respectively, and the obtainable color of cationized cotton fabrics were brighter as compared to the untreated cotton.
\end{abstract}

Index Terms - Cationization, cotton dyeing, marigold dye, rose dye.

\section{INTRODUCTION}

Cotton fabric is natural cellulose fiber, which produces slightly negative charge as being contacted with water owing to the ionization of the hydroxyl group [1], [2]. Because of its electrolyte, anionic dyes are suitable for intensified dye uptake, whereas anionic dyes leads to the waste water and environmental problems [3]. Natural dyes are more interesting due to sustainability, bio-degradability [4] and low toxicity [5]. In this study, marigold and rose were extract for dyeing cotton fabric. Because large amounts of red rose and marigold are major of flowers offered in Thai Temples, the offered flowers increasingly create the huge amount of biological waste. However, these wastes can produce the natural pigment for dyeing fabric.

Natural dyes are one of the alternatives friendlier for the environment, but the natural dyes are low absorbed on cotton [6]. The cationizing agent is used to modify the cationization process to improve dye ability of cotton-dyeing process, color yields and fastness properties compared to the conventional dye process [2], [7].

The objective of this work was to investigate the effects of cationizing agent on the dyeing properties of cotton for marigold and rose extracts. The influences on color values and intensity of cationizing-agent concentration, time and

Manuscript received February 22, 2019; revised April 22, 2019.

M. Nutchawanit and C. Satirapipathkul are with Chulalongkorn University, Thailand (e-mail: matrikan.n@gmail.com, chutimon.s@chula.ac.th).

Rattanaphol Mongkholrattanasit is with Rajamangala University of Technology Phra Nakhon, Thailand (e-mail: Rattanaphol.m@rmutp.ac.th) temperature compared to the untreated cotton were studied. The color values and color strength were determined by spectrophotometer.

\section{MATERIALS AND METHOD}

\section{A. Materials}

Marigolds and roses were waste flowers from Trinity and Ganesha offered at Central World Shopping Plaza, Bangkok. The bleached cotton fabric was received from Thai Phuan community, Ban Mi district, Lopburi, Thailand. The soaping agent was supplied by Boonthawee Chemephan Co, Ltd. (Thailand) and the cationizing agent used in this experiment was STARCAT PD (Polyethylene polyamine) from Star Tech Chemical Industrial Co., Ltd., Bangkok, Thailand.

\section{B. Cationization of Cotton Fabric}

The bleached cotton was treated by being soak in cationizing-agent solution with the variation of cationization concentrations, time and temperatures at a fabric-to-liquor ratio of 1:50 using STARCAT PD to insert cationic groups on cotton surface. The effects of time, temperature and concentration of cationizing agent on color strength $(\mathrm{K} / \mathrm{S})$ and color values $\left(\mathrm{L}^{*}, \mathrm{a}^{*}, \mathrm{~b}^{*}\right)$ were studied, then the dyed cationized cotton with the optimum condition of time, temperature and concentration were compared with the cation-untreated, dyed cotton.

\section{1) The Effects of concentration}

The bleached cotton fabrics were treated in the different cationizing-agent concentrations of $5,10,15$ and $20 \mathrm{~g} / \mathrm{L}$ (in distilled water) at $30^{\circ} \mathrm{C}$ for 60 minutes, then dried in oven at $60^{\circ} \mathrm{C}$ for 10 minutes. After that, the cationized cotton was dyed and measured the color value and color strength.

\section{2) The effects of time}

The bleached cotton fabrics were treated in various time of $15,30,45,60$ and 75 minutes at the $30^{\circ} \mathrm{C}$ by the concentration with the maximum K/S value, then dried in oven at $60^{\circ} \mathrm{C}$ for 10 minutes. After that, the cationized cotton was dyed and measured the color value and color strength.

\section{3) The effects of temperature}

The bleached cotton fabrics were treated with the selected concentration and time presenting the maximum $\mathrm{K} / \mathrm{S}$ value at various temperatures of $30,50,70$ and $90^{\circ} \mathrm{C}$ by heating the solution in water bath, then dried in oven at $60^{\circ} \mathrm{C}$ for 10 minutes. After that, the cationized cotton were dyed and measured the color value and color strength.

\section{Dye Extraction \\ 1) Marigold-dye extraction}

In this experiment, the flower petals were dried in hot-air 
oven at $45-60^{\circ} \mathrm{C}$ for 12 hours before being ground. The ground dried marigold petals were extracted by $95 \%$ ethanol at $60^{\circ} \mathrm{C}$ by heating the solution in water bath with the ground-dried-petal-to-liquor ratio of 1:5. The mixture was left on the magnetic-bar stirrer for 2 hours then filtered by no. 1 Whatman filter paper to remove the residue and dried at $60^{\circ} \mathrm{C}$.

\section{2) Rose-dye Extraction}

In this experiment, the flower petals were dried in hot-air oven at $45-60^{\circ} \mathrm{C}$ for 12 hours before being ground. The ground dried rose petal was extracted by $50 \%$ ethanol at room temperature with the ground-dried-petal-to-liquor ratio of 1:10. The mixture was left on the magnetic-bar stirrer for 90 minutes then filtered by no. 1 Whatman filter paper to remove the residue and dried at $60^{\circ} \mathrm{C}$.

\section{Dyeing Process}

Marigold and rose extracts were dissolved in distilled water with the dye concentration of $40 \mathrm{~g} / \mathrm{L}$. The dye concentrations were determined using a UV-Visible Spectrophotometer based on absorbance at the maximum wavelength, $\lambda_{\max }\left(\lambda_{\max }\right.$ of $360 \mathrm{~nm}$ for marigold dye and $\lambda_{\max }$ of $288.5 \mathrm{~nm}$ for rose dye). The marigold extract dyed the cationized cotton and the untreated cotton fabric by soaking them at $50^{\circ} \mathrm{C}$ for $60 \mathrm{~min}$ in water bath. The rose extract dyed the cationized cotton and the untreated cotton fabric by soaking them at the temperature $30^{\circ} \mathrm{C}$ for $60 \mathrm{~min}$. The fabric-to-liquor ratio of 1:50 was used in both marigold and rose dyes. After dyeing process was done, the dyed samples were rinsed and soaked with non-ionic soaping agent $(2 \mathrm{~g} / \mathrm{L}$ in water) at the fabric-to-liquor ratio of $1: 50,80^{\circ} \mathrm{C}$ for 15 minutes. The dyed samples were rinsed with cold water, dried at room temperature and then measured the $\mathrm{K} / S$ and the color values by spectrophotometer (Macbeth Color Eye 7000).

\section{E. Color Measurement}

The dyed cotton was determined its color value $\left(L^{*}, a^{*}, b^{*}\right)$ and color strength $(K / S)$ by spectrophotometer following the standard procedure. $L^{*}$ value is the measure of lightness $\left(L^{*}=\right.$ 0 is the darkest black, and $L^{*}=100$ is the brightest white), $a^{*}$ and $b^{*}$ are defined the green-red and blue-yellow color components where $a^{*}$ extends from green (negative sign) to red (positive sign) while $b^{*}$ from blue (negative sign) to yellow (positive sign). The color strength $(K / S)$ is automatically analyzed by Kubelka-Munk equation [4] (1).

$$
K / S=(1-R)^{2} / 2 R
$$

where $K$ is the light absorption coefficient, $S$ is scattering coefficient and $R$ is reflectance value at the maximum wavelength of the dyed sample

\section{RESULTS AND DISCUSSION}

\section{A. The Effects of Concentration for Cationization}

The effects of concentration of catiornizing agent to $K / S$ values of cotton fabric dyed by rose and marigold extracts were shown in Fig. 1. The $K / S$ values of the cationized cotton fabric with the marigold dye increased as the concentrations of cationization increased from $0-10 \mathrm{~g} / \mathrm{L}$ which showed that the highest $K / S$ value (20.38) was higher than the $K / S$ of the untreated cotton (16.75) up to $17.81 \%$. In case of rose dye, the $K / S$ values of the cationized cotton fabric increased as the concentrations of cationization increased from 0-15 g/L which displayed that the highest $K / S$ value (2.89) was higher than the $K / S$ of the untreated cotton (0.94) up to 2.08 times. The suitable concentration of cationizing agent for marigold and rose dye are $10 \mathrm{~g} / \mathrm{L}$ and $15 \mathrm{~g} / \mathrm{L}$, respectively. The colors achieved at the optimum cationization concentration were shown in Fig. 2. The result presented the bright-yellow and bright-pink shade of cationized fabric.

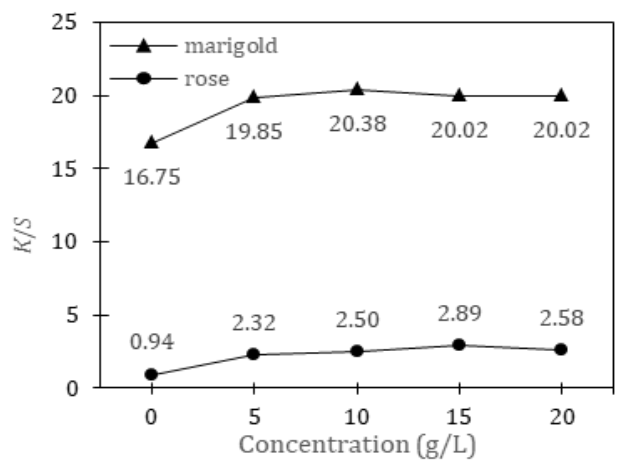

Fig. 1 . The K/S values of the dyed cationized cotton fabric by varying the concentrations for cationization.
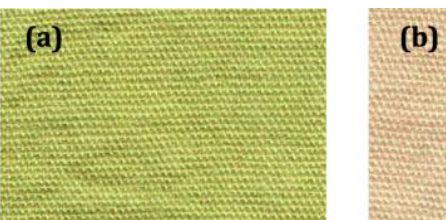

Fig. 2. The colors obtained at the optimum cationic concentration with the marigold dye (a) and the rose dye (b)

\section{B. The Effects of Time for Cationization}

Fig. 3 showed the effects of cationization time on $K / S$ values of the dyed cotton fabric. The $K / S$ value of the cationized cotton fabric with the marigold dye increased as the process time increased from 0-30 minutes and then insignificantly decreased. At 30 minutes, the cationization dyed fabric show the maximum color strength (20.38) which is 1.22 times of the $K / S$ of untreated cotton (16.75). In case of rose, the $K / S$ value of the cationized fabric increased as the process time increased from 0-15 minutes. From 15-75 minutes, there was no significantly change on $K / S$ values, and the optimum time for cationization of rose dye was 15 minutes. At the optimum time, the color strength was 2.88 that was 3.08 times of the $K / S$ values of untreated fabric (0.94). The obtained color of the optimum cationization concentration and time at $30^{\circ} \mathrm{C}$ was bright yellow and pink shown in Fig. 4.

\section{The Effects of Temperature for Cationization}

From the experiment, the optimum temperature for cationization on cotton fabric was studies to improve the dyeability, and the color strength of dyed cotton at the various temperatures was revealed in Fig. 5. The result presented that the dye fabric showed bright-yellow and bright-pink shades shown in Fig. 6. The result also revealed that increased temperature of cationization to $50^{\circ} \mathrm{C}$ enhanced the color strength for marigold and rose dye to 22.49 and 4.06, respectively. The color strength of cationic cotton with the 
marigold dye and the rose dye at $50^{\circ} \mathrm{C}$ were bigger than the color strength of cationized cotton at $30^{\circ} \mathrm{C}$ up to $10.35 \%$ and $49.82 \%$, respectively. The result showed that cationization at $50^{\circ} \mathrm{C}$ was the appropriate temperature for this study.

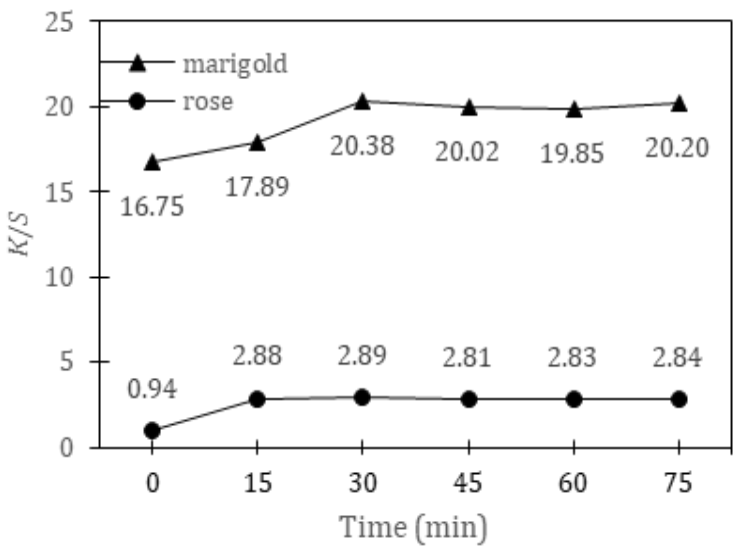

Fig. 3. The K/S value of the dyed cationized cotton fabric by varying time for cationization.

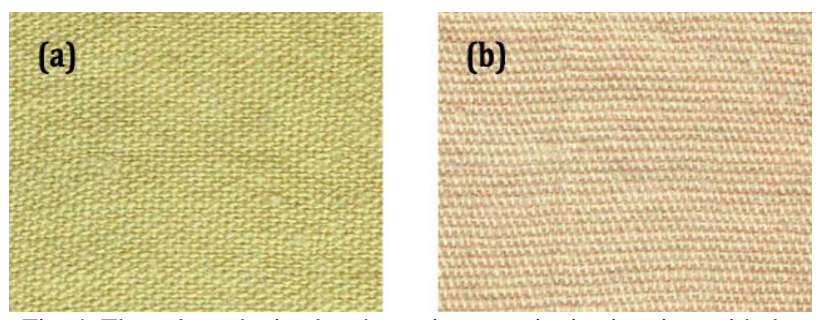

Fig. 4. The colors obtained at the optimum cationization time with the marigold dye (a) and the rose dye (b).

\section{Comparison of Color Values and Color Strength of the}

Chosen Cationization Condition with Color Values and

\section{Color Strength of Untreated Cotton}

According to the optimum concentration, temperature and time of the cationization process, Fig. 7 showed the comparative of $K / S$ values for cationized cotton and untreated cotton. $K / S$ values of cationized cotton was greater than the $K / S$ values of untreated cotton. Table I showed the $K / S$ values, color value $\left(L^{*}, a^{*}, b^{*}\right)$ and color obtained of dyed cotton. The $L^{*}$ values of both marigold and rose dyes were decreased when the concentrations of cationization increased, and the untreated cotton gave the lighter shade as compared to those dyed with a cationizing agent. The untreated cotton dyed with marigold and rose showed a lighter-yellow shade and paler-pink shade, respectively. The $K / S$ of marigold dyeing of the cationized cotton is 1.34 times of the untreated cotton (increased $34.26 \%$ from the untreated cotton), and $b^{*}$ values was increased $11.95 \%$ from the conventional processes. The $b^{*}$ value was raised and showed the positive signs, the color was bright yellow. The $K / S$ values of the rose dyeing on the cationized cotton is 4.31 times of the untreated cotton (increased $331.91 \%$ from untreated cotton) and $a^{*}$ value showed positive signs, the color was bright pink. The $b^{*}$ values are slightly increased while $a^{*}$ values was increased from the conventional processes up to $117.76 \%$.

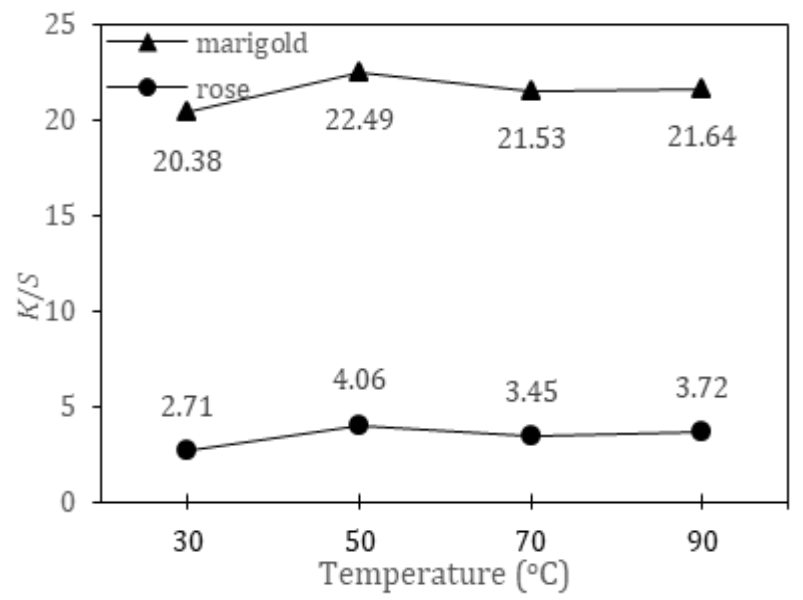

Fig. 5. The K/S values of dyed cationized cotton fabric by varying the temperatures for cationization.
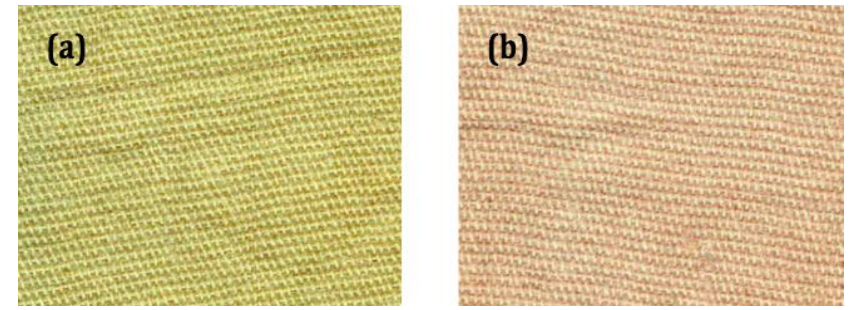

Fig. 6. The colors obtained at the optimum cationization temperature with the marigold dye (a) and the rose dye (b).

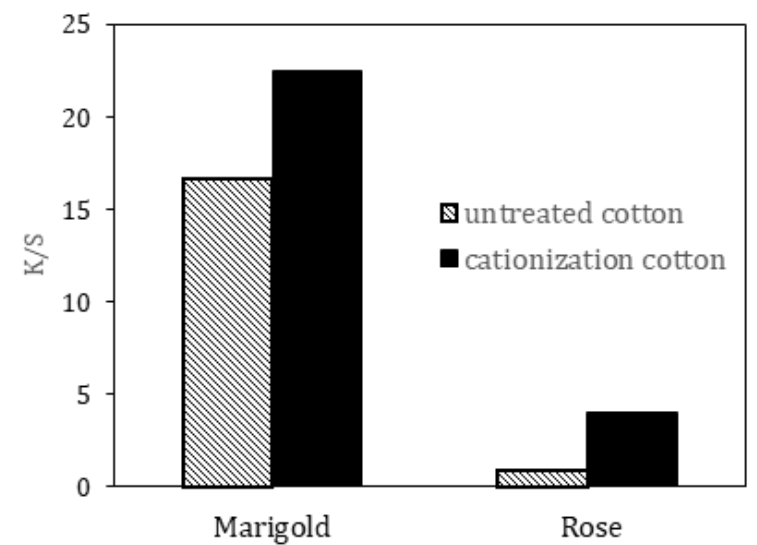

Fig. 7. Comparative of color values and color strength values of cationized cotton and untreated cotton dye with marigold and rose.

TABLE I. THE COLOR VALUES AND COLOR STRENGTH of Dyed UnTREATED CotTON AND CATIONIZED COTTON

\begin{tabular}{|c|c|c|c|c|c|c|}
\hline \multicolumn{2}{|c|}{ CONDITION } & $L^{*}$ & $A^{*}$ & $B^{*}$ & $K / S$ & COLOR OBTAINED \\
\hline \multirow{2}{*}{$\begin{array}{c}\text { MARIGOLD } \\
\text { DYE }\end{array}$} & $\begin{array}{l}\text { UNTREATED } \\
\text { COTTON }\end{array}$ & 72.38 & -1.42 & 38.28 & 16.75 & \\
\hline & $\begin{array}{c}\text { CATIONIZED } \\
\text { COTTON }\end{array}$ & 66.25 & 0.52 & 41.66 & 22.49 & \\
\hline
\end{tabular}




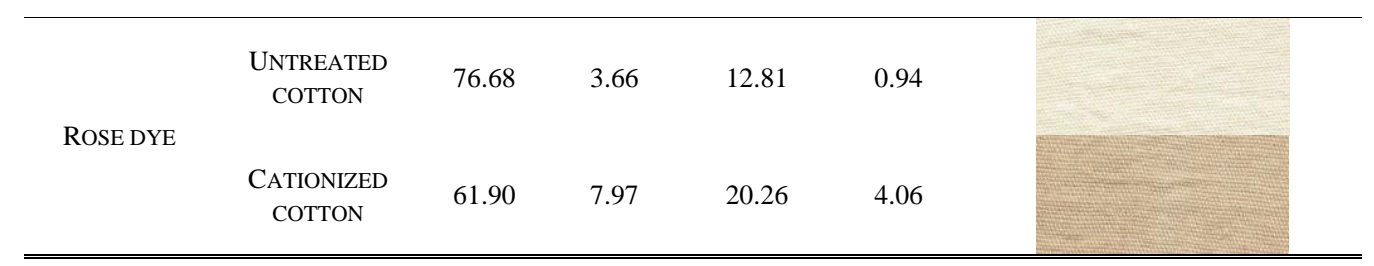

\section{CONCLUSION}

The results presented the cationizing agent increased the color strength $(K / S)$ and $a^{*}, b^{*}$ values for marigold and rose dyes when the $L^{*}$ value was reduced because of the darker shade of dye fabric. The best condition of cationizing process for marigold dye was 30 minutes with the concentration of cationizing agent of $10 \mathrm{~g} / \mathrm{L}$ at $50^{\circ} \mathrm{C}$. In case of rose dye, the most advantageous condition was 15 minutes with the concentration of cationizing agent of $15 \mathrm{~g} / \mathrm{L}$ at $50^{\circ} \mathrm{C}$. Besides, the result reveals that cationization increased the $b^{*}$ values (yellow shade) for marigold dye up to $11.95 \%$ and increased $a^{*}$ values (red shade) up to $117.75 \%$ for rose dye. While the $K / S$ of marigold dyeing of the cationized cotton is 1.34 times of that of untreated cotton, and for the rose dyeing, $K / S$ values of the cationized cotton was 4.31 times of untreated cotton.

\section{ACKNOWLEDGEMENTS}

This research was supported by a research grant from Research and Researchers for Industries (RRI) of Thailand Research Fund (TRF): MSD59I0097. Laboratory support and facility for this work are also provided by the Department of Textile Chemistry Technology, Rajamangala University of Technology Phra Nakhon, Bangkok, Thailand

\section{REFERENCES}

[1] D. P. Chattopahyay, "Cationization of cotton for low-salt or salt-free dyeing," Indian Journal of Fibre \& Textile Research, vol. 26, pp. 108-115, 2001.
[2] S. Acharya, N. Abidi, R. Rajbhandari, and F. Meulewaeter, "Chemical cationization of cotton fabric for improved dye uptake," Cellulose., vol. 21, pp. 4693-4706, 2014.

[3] M. M. Kamel, M. M. El Zawahry, N. S. E. Ahmed, and F. Abdelghaffar, "Ultrasonic dyeing of cationized cotton fabric with natural dye. Part 1: Cationization of cotton using Solfix E," Ultrasonics Sonochemistry, vol. 16, pp. 243-249, 2009.

[4] G. Erkan, K. Senguil, and S. Kaya, "Dyeing of white and indigo dyed cotton fabrics with Mimosa tenuiflora extract," Journal of Saudi Chemical Society, vol. 18, no. 2, pp. 139-148, 2014.

[5] R. Mongkholrattanasit, C. Klaichoi, J. Sarnium, P. Jareonsapyanant, N Sasivatchutikool, J. Pattavanitch, and N. Rungruangkitkrai, "Effect of dye concentration on UV protection property of silk fabric dyed with purple corn cob using pre-mordanting method," Advanced Materials Research, vol. 1010-1012, Trans Tech Publications, pp. 508-511, Switzerland, 2014

[6] S. Eom, D. Shin, and K. Yoon, "Improveing the dyeability of natural colorant on cotton by cationization," Indian Journal of Fibre \& Textile Research, vol. 26, pp. 425-431, 2001

[7] M. Montazar, R. M. A. Malek, and A. Rahimi, "Salt free reactive dyeing of cationized cotton," Fibers and Polymers, vol. 8, no. 6, pp. 608-612, 2007.

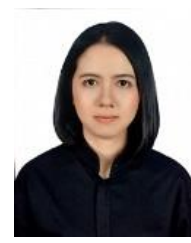

Matrikan Nutchawanit was born in Bangkok, Thailand, January 19, 1991. She received B.E. degree in chemica engineering from Thammasat University, Bangkok, Thailand in 2013

In 2012, she was a student intern in the student Internship Program at TOC Glycol Co., Ltd., Thailand. In 2013-2015, she joined the SFC excellence Co., Ltd., as an ISO and Quality assurance officer

Miss Nutchawanit is a graduate student in Department of Chemical Engineering, Faculty of Engineering, Chulalongkorn University, Bangkok, Thailand. 